Alejandro Suarez-de-la-

Rica' ${ }^{1}$

Patricia Serrano ${ }^{2}$

Rodrigo de-la-Oliva ${ }^{2}$

Pedro Sánchez-Díaz ${ }^{2}$

Pilar Molinero ${ }^{2}$

Iker Falces-Romero ${ }^{3}$

Carlos Ferrando ${ }^{4}$

Jordi Rello ${ }^{5}$

Emilio Maseda'

\section{Secondary infections in mechanically ventilated patients with COVID-19: An overlooked matter?}

\begin{abstract}
Department of Anesthesiology and Surgical Critical Care. Hospital Universitario Marqués de Valdecilla. Santander. Spain.

${ }^{2}$ Department of Anesthesiology and Surgical Critical Care. Hospital Universitario La Paz. Madrid. Spain.

${ }^{3}$ Department of Microbiology and Parasitology. Hospital Universitario La Paz. Madrid. Spain.

${ }^{4}$ Department of Anesthesiology and Surgical Critical Care. Hospital Clínic. Barcelona. Spain

${ }^{5}$ Centro de Investigación Biomedica en Red (CIBERES), Instituto de Salud Carlos III, Madrid, Spain; Vall d'Hebron Institute of Research (VHIR), Barcelona, Spain. Scientific Research, CHU Nîmes, Nîmes, France.
\end{abstract}

Article history

Received: 25 February 2021; Accepted: 8 March 2021; Published: 23 March 2021

\section{ABSTRACT}

Introduction. The susceptibility to infection probably increases in COVID-19 patients due to a combination of virus and drug-induced immunosuppression. The reported rate of secondary infections was quite low in previous studies. The objectives of our study were to investigate the rate of secondary infections, risk factors for secondary infections and risk factors for mortality in COVID-19 critically ill patients.

Material and methods. We performed a single-center retrospective study in mechanically ventilated critically ill COVID-19 patients admitted to our Critical Care Unit (CCU). We recorded the patients' demographic data; clinical data; microbiology data and incidence of secondary infection during CCU stay, including ventilator-associated pneumonia (VAP) and nosocomial bacteremia (primary and secondary).

Results. A total of 107 patients with a mean age 62.2 \pm 10.6 years were included. Incidence of secondary infection during CCU stay was 43.0\% (46 patients), including nosocomial bacteremia (34 patients) and VAP (35 patients). Age was related to development of secondary infection (65.2 \pm 7.3 vs. $59.9 \pm 12.2$ years, $p=0.007)$. Age $\geq 65$ years and secondary infection were independent predictors of mortality $(\mathrm{OR}=2.692$, $95 \% \mathrm{Cl} 1.068-6.782, \mathrm{p}<0.036$; and $\mathrm{OR}=3.658,95 \% \mathrm{Cl} 1.385-$ $9.660, p=0.009$, respectively). The hazard ratio for death within 90 days in the $\geq 65$ years group and in patients infected by antimicrobial resistant pathogens was 1.901 (95\% Cl 1.198$3.018 ; p=0.005$ by log-rank test) and 1.787 (95\% Cl 1.023$3.122 ; p=0.036$ by log-rank test), respectively.

Correspondence:

Alejandro Suarez-de-la-Rica

Department of Anesthesiology and Surgical Critical Care. Hospital Universitario Marqués de

Valdecilla. Santander. Spain

E-mail: alejandro.suarez.delarica@gmail.com

Emilio Maseda

Department of Anesthesiology and Surgical Critical Care. Hospital Universitario Marqués de Valdecilla. Santander. Spain.

E-mail: emilio.maseda@gmail.com
Conclusions. Our data suggest that the incidence of secondary infection and infection by antimicrobial resistant pathogens is very high in critically ill patients with COVID-19 with a significant impact on prognosis.

Keywords: Acute respiratory distress syndrome, COVID-19, mechanical ventilation, infection, ventilator-associated pneumonia, bacteremia

\section{Infecciones secundarias en pacientes ventilados mecánicamente con COVID-19: ¿un asunto pasado por alto?}

\section{RESUMEN}

Introducción. En pacientes con COVID-19 la susceptibilidad a la infección se encuentra probablemente incrementada debido a una combinación de inmunosupresión farmacológica y provocada por el virus. La incidencia de infecciones secundarias descrita en estudios previos es bastante baja. Los objetivos de nuestro estudio consistieron en investigar la incidencia de infecciones secundarias, los factores de riesgo de infecciones secundarias y los factores de riesgo de mortalidad en pacientes críticos con COVID-19.

Material y métodos. Realizamos un estudio retrospectivo unicéntrico en pacientes críticos COVID-19 que precisaron ventilación mecánica ingresados en nuestra Unidad de Cuidados Críticos (UCC). Recopilamos datos demográficos; clínicos; microbiológicos y la incidencia de infección secundaria durante la estancia en la UCC, incluyendo neumonía asociada a ventilación mecánica (NAVM) y bacteriemia nosocomial (primaria y secundaria).

Resultados. Se incluyeron un total de 107 pacientes con una edad media de 62,2 $\pm 10,6$ años. La incidencia de infección secundaria durante el ingreso en la UCC fue 43,0\% (46 pacientes), incluyendo bacteriemia nosocomial (34 pacientes) y NAVM (35 pacientes). La edad se asoció con el desarrollo de infección secundaria $(65,2 \pm 7,3$ vs. 59,9 $\pm 12,2$ años; $p=0,007)$. 
La edad $\geq 65$ años y la infección secundaria fueron predictores independientes de mortalidad ( $O R=2,692$; IC 95\% 1,068-6,782; $\mathrm{p}<0,036$; y $\mathrm{OR}=3,658$; IC 95\% 1,385-9,660; $p=0,009$, respectivamente). Hazard ratio para mortalidad a los 90 dias en el grupo $\geq 65$ años y en pacientes infectados por patógenos resistentes a antimicrobianos fue 1,901 (IC 95\% 1,198-3,018; $p=$ 0,005 por test log-rank) y 1,787 (IC 95\% 1,023-3,122; $p=0,036$ por test log-rank), respectivamente.

Conclusiones. Nuestros datos sugieren que la incidencia de infección secundaria y la infección por patógenos resistentes a antimicrobianos es muy alta en pacientes críticos con COVID-19 con un impacto significativo en el pronóstico.

Palabras clave: Síndrome de distrés respiratorio agudo, CoVID-19, ventilación mecánica, infección, neumonía asociada a ventilación, bacteriemia

\section{INTRODUCTION}

SARS-CoV-2 pandemic has struck more than 41 million people worldwide as of October $23^{\text {th }}, 2020$ [1]. Clinical manifestations range from asymptomatic infection to severe viral pneumonia with acute respiratory distress syndrome requiring ICU admission and mechanical ventilation. The susceptibility to infection probably increases in COVID-19 patients due to a combination of virus- and drug-induced immunosuppression. It is challenging to discriminate between isolated COVID-19 viral and extra bacterial or fungal infection, and there is paucity of data, mainly in critically ill patients [2]. The reported rate of secondary infections was quite low in previous studies [3]. Underestimating the rate of secondary infections would directly impact the prognosis. The primary objective of our study was to investigate the rate of secondary infections in COVID-19 critically ill patients. The secondary objectives were to analyze risk factors for secondary infections and risk factors for mortality.

\section{MATERIAL AND METHODS}

Study population. We performed a single-center retrospective study in mechanically ventilated critically ill COVID-19 patients admitted to the Critical Care Unit (CCU) of the University Hospital La Paz (Madrid, Spain), a 1300- bed teaching hospital, between $16^{\text {th }}$ of March 2020 and $17^{\text {th }}$ of May 2020. During this period, a total of 3007 patients with COVID-19 were admitted to the hospital. Our unit had a total of 83 beds during the pandemic period, including all patients who needed invasive mechanical ventilation due to COVID-19 related acute respiratory distress syndrome (ARDS).

COVID-19 was defined as a positive real-time reverse transcriptase polymerase chain reaction (RT-PCR) for SARS-CoV-2 from a nasopharyngeal swab or an endotracheal aspirate.

We recorded the patients' demographic data; clinical data, including use of systemic corticosteroids and tocilizumab during the hospital stay; microbiology data and incidence of secondary infection during CCU stay, including ventilator-associated pneumonia (VAP) and nosocomial bacteremia (primary and secondary), according to Centers for Disease Control (CDC) criteria $[4,5]$.
Furthermore, 90-day mortality was recorded for all patients.

VAP was defined with clinical, radiological and microbiologic data, with identification of at least 1 bacterial species by conventional culture, with a threshold of $\geq 10^{5}$ colony forming units in endotracheal aspirates [4]. Bronchoalveolar lavage was not performed due to contraindication by risk of aerosolization. Aspergillus spp isolation was not considered significant without bronchoalveolar lavage and serum galactomannan antigen. Candida spp. and Enterococcus spp. isolation in respiratory cultures was considered colonization.

Nosocomial bacteremia was considered when positive blood cultures were recovered at least $48 \mathrm{~h}$ after the hospital admission. Coagulase-negative staphylococci considered as contaminants (only one positive blood culture) were excluded [5].

Secondary infection was defined as development of VAP or nosocomial bacteremia. We did not recorded data regarding urinary tract infections due to difficulties in distinguishing between colonization and infection. Isolated bacteria presenting extended-spectrum $\beta$-lactamases (ESBL) and/or carbapenemase production (for gram-negatives) and/or high-level aminoglycoside resistance and/or resistance to vancomycin and/or methicillin resistance (for gram-positives) were considered antimicrobial resistant pathogens (ARP) [6].

Both endotracheal aspirates and blood cultures were requested by the attending physician in case of clinical suspicion with radiological and/or laboratory findings. Patients with no blood or respiratory cultures were considered not to have secondary infections.

Statistical analysis. The categorical variables were described by frequency $(\%)$, and quantitative variables by mean (SD).

In univariate analysis, the effect of factors associated with secondary infection and mortality was analyzed by Fisher exact test for categorical variables and the Student's T-Test for quantitative variables. Logistic regression models (step-wise procedure) were performed using the 90- day mortality and secondary infection as dependent variables, and those with clinico-epidemiological relevance and/or showing differences in univariate analysis as independent variables. The limit of 5 to 10 events (or nonevents, whichever is less) per introduced variable was not exceeded.

Kaplan-Meier survival curves were constructed to show cumulative mortality over the 90-day period, and cox regression analysis was performed. Data were analyzed with SAS 9.3 statistical software (SAS Institute Inc, Cary, NC). A P value lower than 0.05 was considered statistically significant.

Ethics. A national database (code PI2020069) approved by the institutional review board was used to collect data.

\section{RESULTS}

A total of 107 patients with a mean age $62.2 \pm 10.6$ years were included. Incidence of secondary infection during CCU 


\begin{tabular}{|c|c|c|c|c|}
\hline Table 1 & Demographic and clini & ata & & \\
\hline Variable & Total $(n=107)$ & $\begin{array}{l}\text { Secondary infection } \\
\qquad(n=46)\end{array}$ & $\begin{array}{l}\text { No secondary infection } \\
\qquad(\mathrm{n}=61)\end{array}$ & $p$ \\
\hline Male, n (\%) & $76(71)$ & $33(71.7)$ & $43(70.5)$ & 1 \\
\hline Age (years), mean $\pm S D$ & $62.2 \pm 10.6$ & $65.2 \pm 7.3$ & $59.9 \pm 12.2$ & 0.007 \\
\hline \multicolumn{5}{|l|}{ Comorbidities, n (\%) } \\
\hline AHTN & $53(49.5)$ & $26(56.5)$ & $27(44.2)$ & 0.244 \\
\hline DM & $21(19.6)$ & $8(17.4)$ & $13(21.3)$ & 0.806 \\
\hline CAD & $4(3.7)$ & $4(8.7)$ & $0(0)$ & No value \\
\hline Cardiac failure & $6(5.7)$ & $3(5.0)$ & $3(6.5)$ & No value \\
\hline PAD & $11(10.3)$ & $7(15.2)$ & $4(6.5)$ & No value \\
\hline Chronic renal failure & $6(5.6)$ & $2(4.2)$ & $4(6.7)$ & No value \\
\hline Obesity & $9(8.4)$ & $3(6.4)$ & $6(10.0)$ & No value \\
\hline Respiratory disease & $17(15.9)$ & $9(19.6)$ & $8(13.1)$ & 0.428 \\
\hline OSAS & $8(7.5)$ & $3(6.4)$ & $5(8.3)$ & No value \\
\hline Solid tumor & $11(10.3)$ & $6(12.8)$ & $5(8.3)$ & No value \\
\hline HIV & $1(0.9)$ & $0(0.0)$ & $1(1.7)$ & No value \\
\hline Corticosteroids, n (\%) & $82(76.6)$ & $35(76.0)$ & $47(77.0)$ & 1 \\
\hline Tocilizumab, n (\%) & $50(46.7)$ & $18(38.3)$ & $32(53.3)$ & 0.240 \\
\hline
\end{tabular}

AHTN: arterial hypertension; DM: diabetes mellitus; CAD: coronary arterial disease; PAD: peripheral arterial disease; OSAS: obstructive sleep apnea syndrome

\section{\begin{tabular}{l|l} 
Table 2 & Isolated species in respiratory and blood
\end{tabular} cultures}

\begin{tabular}{lcc}
\hline Isolated species, $\mathrm{n}(\%)$ & Respiratory cultures & Blood cultures \\
\hline Enterococcus faecalis & $0(0)$ & $14(28.5)$ \\
\hline Klebsiella spp. & $9(25.7)$ & $5(10.2)$ \\
\hline Pseudomonas aeruginosa & $11(31.4)$ & $2(4.0)$ \\
\hline Candida spp. & $0(0)$ & $12(24.4)$ \\
\hline Staphylococcus aureus & $8(22.8)$ & $6(12.2)$ \\
\hline Escherichia coli & $4(11.4)$ & $4(8.2)$ \\
\hline Enterococcus faecium & $0(0)$ & $5(10.2)$ \\
Serratia spp. & $2(5.7)$ & $0(0)$ \\
\hline Enterobacter spp. & $1(2.8)$ & $0(0)$ \\
Other & $0(0.0)$ & $1(2.0)$ \\
\hline
\end{tabular}

stay was $43.0 \%$ ( 46 patients), including nosocomial bacteremia $(32.1 \%, 34$ patients) and VAP $(32.7 \%, 35$ patients). Coagulase-negative staphylococci were considered contaminants as only one blood culture was positive.

In univariate analysis, age was related to development of secondary infection ( $65.2 \pm 7.3$ vs. $59.9 \pm 12.2$ years, $p=0.007$ ). Nei- ther the use of systemic corticosteroids nor the use of tocilizumab during hospital stay was related to secondary infections (table 1).

Microbiology data are presented in table 2. A total of 17 patients (15.9\%) had infections produced by ARP. Eleven patients had extended-spectrum beta-lactamases producing Enterobacterales, one patient carbapenemase-producing Enterobacterales (VIM-producing Klebsiella pneumoniae) and five patients methicillin-resistant Staphylococcus aureus. Neither vancomycin-resistant Enterococci nor carbapenemase-producing Pseudomonas aeruginosa were present. Aspergillus spp. was identified in endotracheal aspirates from 4 patients. However, this finding was not considered significant due to the absence of bronchoalveolar lavage and serum galactomannan antigen.

The 90-day mortality rate was 69.2\% (74 patients). Mortality was higher in older patients (mean age $64.9 \pm 8.2$ vs. $56.1 \pm$ 13.0 years, $p=0.001)$, in the case of a secondary infection $(84.8 \%$ vs. $57.4 \%, p=0.003)$, bacteremia ( $85.3 \%$ vs. $61.6 \%, p=0.014$ ), $\operatorname{VAP}(82.9 \%$ vs. $62.5 \%, p=0.044)$, and in patients infected by ARP ( $94.1 \%$ vs. $64.4 \%, p=0.020$ ). Corticosteroids and tocilizumab administration and comorbidities were not related to mortality.

In multivariate analysis, age $\geq 65$ years and secondary infection were independent predictors of mortality $(\mathrm{OR}=2.692$, 95\% Cl 1.068-6.782, $\mathrm{p}<0.036$; and $\mathrm{OR}=3.658,95 \% \mathrm{Cl} 1.385-$ $9.660, p=0.009$, respectively). 


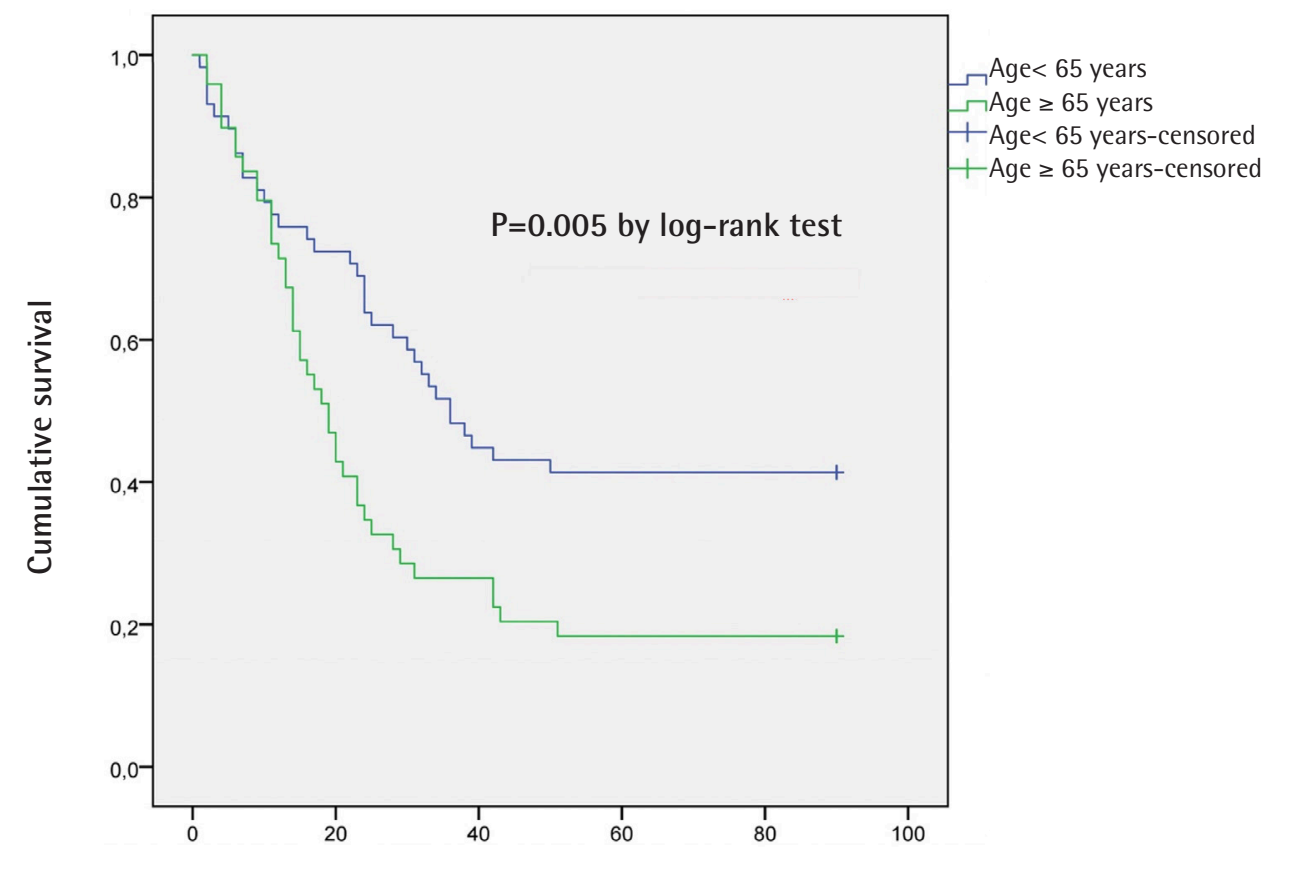

Time from ICU admission (days)

\section{Figure $1 \quad$ Kaplan-Meier curves for 90 -day survival in patients with age $<65$ years and $\geq 65$ years}

The hazard ratio for death within 90 days in the $\geq 65$ years group compared to <65 years group was 1.901 (95\% Cl 1.198-3.018; $p=0.005$ by log-rank test). Log-rank test in Kaplan-Meier curves for patients with and without secondary infection did not reach statistical significance $(p=0.085)$. The hazard ratio for death within 90 days in patients infected by ARP was 1.787 (95\% Cl 1.023-3.122; $p=0.036$ by log-rank test). The Kaplan-Meier curves for 90-day survival are shown in figure 1 and 2.

\section{DISCUSSION}

Our study suggests that COVID-19 mechanically ventilated patients could have high incidences of bacteremia, VAP and infections by ARP. Enterococci were the most isolated agents.

The incidence of secondary infection in critically ill COVID-19 patients in our study is $43.0 \%$. This percentage is higher than the one previously reported by Ferrando et al [7], with an incidence of respiratory bacterial infection and bacteremia of 27.1\% and 26.2\% respectively. Meanwhile, Yang et al [3] (incidence of pneumonia and bacteremia of $11.5 \%$ and $2 \%$, respectively) and Barrasa et al [8] (incidence of secondary infection of 12.5\%) described a lower incidence. Feng et al declared an incidence of secondary bacterial infection of $34.4 \%$ in the more severe subgroup of COVID-19 patients [9], and, in the study performed by Ripa et al, 40 patients out of 86 (46.5\%) admitted to intensive care developed at least one secondary infection [10]. Moreover, a recent report described a quite high incidence as well [11]. Our cohort includes only patients under invasive mechanical ventilation, what may explain partially these differences. Among non-critically ill hospitalized patients, the incidence of secondary nosocomial infection during hospital stay varies from $6.1 \%$ to $15.5 \%$ [12-13]. The reported incidence of secondary infections in patients with ARDS of other causes is quite lower. Villar et al found an incidence of $24 \%$ in treatment group and $25 \%$ in placebo group in a previous randomized controlled trial in patients with established moderate-to-severe ARDS [14].

This high incidence of secondary infection could be partially justified by an altered T Iymphocyte immune response in COVID-19 patients. Preliminary flow cytometry determination of blood immune cells demonstrated a reduction in absolute numbers of total $\mathrm{T}$ lymphocytes (CD4+, CD8+, and regulatory T cells) [15]. Further studies are needed to corroborate these findings. Our city, Madrid, was the epicenter of the pandemic in Spain. Consequently, our healthcare system suffered an unprecedented pressure. Besides, the correct use of personal protective equipment could be challenging during the pandemic period. These two conditions could have led to a reduced compliance with VAP and bacteremia prevention guidelines, what would contribute to a high infection rate. 


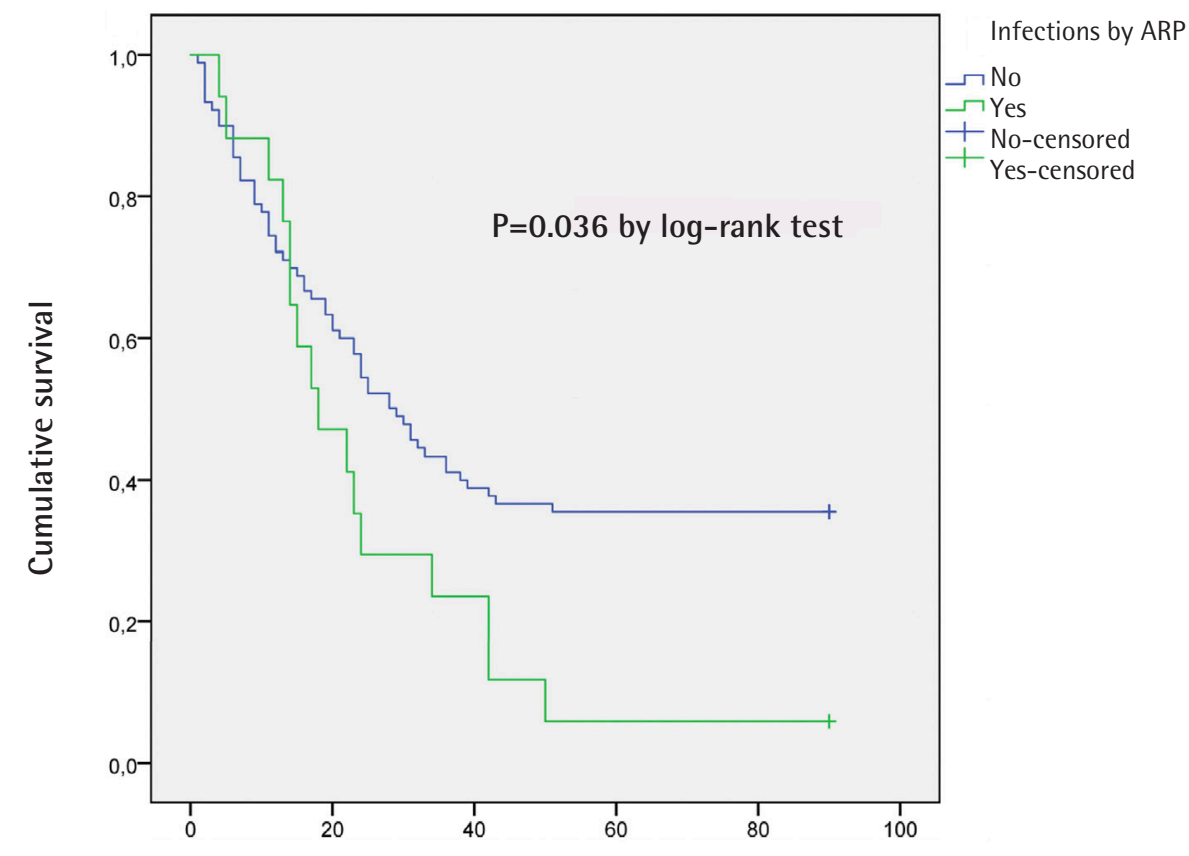

Time from ICU admission (days)

Figure 2 Kaplan-Meier curves for 90-day survival in patients with and without infection by antimicrobial resistant pathogens (ARP)

In our cohort of patients, secondary infection and infection by ARP had an impact on 90-day mortality. There is a need to improve compliance to prevention guidelines and antimicrobial stewardship programs in order to reduce the development of infection and resistance [16]. Antibiotic prescriptions increase significantly during a viral pandemic as COVID-19 [11]. This could have a long-term impact on the availability of antibiotics and drug resistance.

Another important finding of our study is the lack of relation between the use of corticosteroids and tocilizumab and the development of infections and mortality, in contrast to the conclusions of Sommers et al with a lower mortality rate but a higher infection occurrence related to the use of tocilizumab [17]. Recent randomized controlled trials in non-critically ill patients did not find any difference in mortality between tocilizumab and placebo groups [18-20]. Ferrando et al also showed no association between the use of corticosteroids and tocilizumab and mortality [7]. The RECOVERY trial results suggest that corticosteroids may be beneficial in patients with COVID-19, mostly in patients under mechanical ventilation [21]. Nevertheless, assessing mortality at 28 days may not be optimal, given that severe COVID-19 patients under mechanical ventilation often require prolong ICU and hospital stay, beyond day-28. Moreover, late superinfection may occur after day 28 , what may impact the prognosis [22]. In our cohort of patients, corticosteroids administration did not affect neither secondary infection rate nor mortality at 90 days.
Our study has several limitations: the retrospective nature of the analysis; the lack of invasive modalities to help diagnose VAP (bronchoalveolar lavage) due to contraindication by risk of aerosolization and difficulties in diagnosis of VAP with traditional criteria [23]; the absence of data regarding dose and duration of corticosteroids, tocilizumab, antibiotic treatment (since appropriate empiric antibiotic treatment affects mortality), origin of bacteremia (primary or secondary) and incidence density of VAP. Given that severity-of-illness scores are similar at admission in COVID-19 and our data are not adjusted by severity, we cannot rule out that infection by resistant pathogens was simply a marker of severity. Patients exposed to other endemic colonization by ARP may be exposed to different pathogens, and this affects generalization. On the other hand, to our knowledge, this is the first study that focus on secondary infections in mechanically ventilated, critically ill patients with COVID-19. These data have important implications for infection control and antimicrobial stewardship in these patients.

Our data suggest that the incidence of secondary infection and infection by ARP is very high in critically ill patients with COVID-19 with a significant impact on prognosis with potential differences with other causes of ARDS. Compliance to prevention guidelines and antimicrobial stewardship programs should be improved to reduce the development of infection and resistance. Further multicenter studies in other regions and with larger cohorts would help to identify the drivers of 
secondary infections in critically ill COVID-19 patients and implications on antimicrobial stewardship.

\section{ACKNOWLEDGEMENTS}

Statistical analyses were performed by the Biostatistics Unit of Hospital Universitario La Paz, Madrid, Spain.

\section{FUNDING}

None to declare

\section{CONFLICTS OF INTEREST}

All authors declare they have no conflicts of interest.

\section{REFERENCES}

1. Coronavirus Disease (COVID-19) Situation Reports. https://www. who.int/emergencies/diseases/novel-coronavirus-2019/situation-reports (accessed October 27, 2020).

2. Bassetti M, Kollef MH, Timsit JF. Bacterial and fungal superinfections in critically ill patients with COVID-19. Intensive Care Med. 2020;46(11):2071-2074. doi: 10.1007/s00134-020-06219-8.

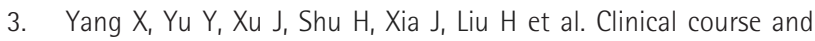
outcomes of critically ill patients with SARS-CoV-2 pneumonia in Wuhan, China: a single-centered, retrospective, observational study [published correction appears in Lancet Respir Med. 2020; 8(4):e26]. Lancet Respir Med. 2020;8(5):475-481. doi:10.1016/ S2213-2600(20)30079-5

4. Torpy JM, Lynm C, Glass RM. JAMA patient page. Ventilator-associated pneumonia. JAMA. 2007;297(14):1616. doi:10.1001/ jama.297.14.1616

5. Centers for Disease Control and Prevention/ National Healthcare Safety Network. Identifying Healthcare-associated Infections (HAl) for NHSN Surveillance. January 2017. Available from: https://www. cdc.gov/nhsn/pdfs/pscmanual/2psc_identifyinghais_nhsncurrent. pdf.

6. Maseda E, Ramírez S, Picatto P, Peláez-Peláez E, García-Bernedo C, Ojeda-Betancur $\mathrm{N}$ et al. Critically ill patients with community-onset intraabdominal infections: Influence of healthcare exposure on resistance rates and mortality. PLoS One. 2019;14(9):e0223092. doi:10.1371/journal.pone.0223092

7. Ferrando C, Mellado-Artigas R, Gea A, Arruti E, Aldecoa C, Bordell $A$ et al. Patient characteristics, clinical course and factors associated to ICU mortality in critically ill patients infected with SARSCoV-2 in Spain: a prospective, cohort, multicentre study. Rev Esp Anestesiol Reanim. 2020; 67(8): 425-37. https://doi.org/10.1016/j. redar.2020.07.003

8. Barrasa H, Rello J, Tejada S, Martín A, Balziskueta G, Vinuesa C et al. SARS-CoV-2 in Spanish Intensive Care Units: Early experience with 15-day survival in Vitoria. Anaesth Crit Care Pain Med. 2020; 39(5):553-561. doi:10.1016/j.accpm.2020.04.001
9. Feng $Y$, Ling $Y$, Bai T, Xie Y, Huang J, Li J et al. COVID-19 with Different Severities: A Multicenter Study of Clinical Features. Am J Respir Crit Care Med. 2020; 201(11):1380-1388. doi:10.1164/rccm.202002-04450C

10. Ripa M, Galli L, Poli A, Oltolini C, Spagnuolo V, Mastrangelo A et al. Secondary Infections in Patients Hospitalized with COVID-19: Incidence and Predictive Factors. Clin Microbiol Infect 2020. doi: 10.1016/j.cmi.2020.10.021 .

11. Barrasa $H$, Martín A, Maynar J, Rello J, Fernández-Torres M, Aguirre-Quiñonero A, Canut-Blasco A; Alava COVID-19 Study Investigators. High rate of infections during ICU admission of patients with severe SARS-CoV-2 pneumonia: A matter of time? J Infect. 2020:S0163-4453(20)30761-1. doi: 10.1016/j.jinf.2020.12.001.

12. Hughes S, Troise O, Donaldson H, Mughal N, Moore LSP. Bacterial and fungal coinfection among hospitalized patients with COVID-19: a retrospective cohort study in a UK secondary-care setting. Clin Microbiol Infect. 2020; 26(10):1395-1399. doi:10.1016/j. cmi.2020.06.025

13. Langford BJ, So M, Raybardhan S, Leung V, Westwood D, MacFadden DR et al. Bacterial co-infection and secondary infection in patients with COVID-19: a living rapid review and meta-analysis. Clin Microbiol Infect. 2020; 26(12):1622-1629. doi: 10.1016/j. cmi.2020.07.016.

14. Villar J, Ferrando C, Martínez D, Ambrós A, Muñoz T, Soler JA et al. Dexamethasone treatment for the acute respiratory distress syndrome: a multicentre, randomised controlled trial. Lancet Respir Med. 2020;8(3):267-276. doi: 10.1016/S2213-2600(19)30417-5.

15. Guillon A, Hiemstra PS, Si-Tahar M. Pulmonary immune responses against SARS-CoV-2 infection: harmful or not?. Intensive Care Med. 2020;46(10):1897-1900. doi: 10.1007/s00134-020-06170-8.

16. Huttner BD, Catho G, Pano-Pardo JR, Pulcini C, Schouten J. COVID-19: don't neglect antimicrobial stewardship principles! Clin Microbiol Infect 2020; 26:808-10. doi: 10.1016/j.cmi.2020.04.024

17. Somers EC, Eschenauer GA, Troost JP, Golob JL, Gandhi TN, Wang L et al. Tocilizumab for treatment of mechanically ventilated patients with COVID-19 [published online ahead of print, 2020 Jul 11]. Clin Infect Dis. 2020; ciaa954. doi:10.1093/cid/ciaa954

18. Stone JH, Frigault MJ, Serling-Boyd NJ, Fernandes AD, Harvey L, Foulkes AS et al. Efficacy of Tocilizumab in Patients Hospitalized with Covid-19. N Engl J Med. 2020;383(24):2333-2344. doi: 10.1056/NEJMoa2028836.

19. Salvarani C, Dolci G, Massari M, Merlo DF, Cavuto S, Savoldi L et al. Effect of Tocilizumab vs Standard Care on Clinical Worsening in Patients Hospitalized With COVID-19 Pneumonia: A Randomized Clinical Trial. JAMA Intern Med 2021;181(1):24-31. doi: 10.1001/ jamainternmed.2020.6615.

20. Hermine 0 , Mariette $X$, Tharaux $P L$, Resche-Rigon $M$, Porcher $R$, Ravaud P. Effect of Tocilizumab vs Usual Care in Adults Hospitalized With COVID-19 and Moderate or Severe Pneumonia: A Randomized Clinical Trial. JAMA Intern Med 2021;181(1):32-40. doi: 10.1001/ jamainternmed.2020.6820.

21. Horby P, Lim WS, Emberson JR, Mafham M, Bell $J L$, Linsell $L$ et al. Dexamethasone in Hospitalized Patients with Covid-19 - Prelim- 
inary Report. N Engl J Med. 2020; NEJMoa2021436. doi:10.1056/ NEJMoa2021436

22. De Backer D, Azoulay E, Vincent JL. Corticosteroids in severe COVID-19: a critical view of the evidence. Crit Care. 2020;24(1):627. doi:10.1186/s13054-020-03360-0

23. François $B$, Laterre $P F$, Luyt $C E$, Chastre J. The challenge of ventilator-associated pneumonia diagnosis in COVID-19 patients. Crit Care. 2020; 24(1):289. doi: 10.1186/s13054-020-03013-2. 